\title{
Cinnamon Counteracts the Negative Effects of a High Fat/ High Fructose Diet on Behavior, Brain Insulin Signaling and Alzheimer-Associated Changes
}

\author{
Richard A. Anderson ${ }^{1 *}$, Bolin Qin ${ }^{1,2}$, Frederic Canini ${ }^{3,5}$, Laurent Poulet ${ }^{3,4}$, Anne Marie Roussel ${ }^{4}$ \\ 1 Diet, Genomics, and Immunology Laboratory, Beltsville Human Nutrition Research Center, Agricultural Research Service, United States Department of \\ Agriculture, Beltsville, Maryland, United States of America, 2 Integrity Nutraceuticals International, Spring Hill, Tennessee, United States of America, $\mathbf{3}$ Army \\ Institute for Research in Biology, Grenoble, France, 4 National Institute for Health, Joseph Fourier University, Grenoble, France, 5 Ecole du Val de Grâce, 1 \\ place Laveran, Paris, France
}

\begin{abstract}
Insulin resistance leads to memory impairment. Cinnamon $(\mathrm{CN})$ improves peripheral insulin resistance but its effects in the brain are not known. Changes in behavior, insulin signaling and Alzheimer-associated mRNA expression in the brain were measured in male Wistar rats fed a high fat/high fructose (HF/HFr) diet to induce insulin resistance, with or without $\mathrm{CN}$, for 12 weeks. There was a decrease in insulin sensitivity associated with the HF/HFr diet that was reversed by $\mathrm{CN}$. The $\mathrm{CN}$ fed rats were more active in a $\mathrm{Y}$ maze test than rats fed the control and HF/HFr diets. The $\mathrm{HF} / \mathrm{HFr}$ diet fed rats showed greater anxiety in an elevated plus maze test that was lessened by feeding $\mathrm{CN}$. The $\mathrm{HF} / \mathrm{HFr}$ diet also led to a down regulation of the mRNA coding for GLUT1 and GLUT3 that was reversed by CN in the hippocampus and cortex. There were increases in Insr, Irs1 and Irs2 mRNA in the hippocampus and cortex due to the HF/HFr diet that were not reversed by $\mathrm{CN}$. Increased peripheral insulin sensitivity was also associated with increased glycogen synthase in both hippocampus and cortex in the control and HF/HFr diet animals fed CN. The $\mathrm{HF} / \mathrm{HFr}$ diet induced increases in mRNA associated with Alzheimers including PTEN, Tau and amyloid precursor protein (App) were also alleviated by $\mathrm{CN}$. In conclusion, these data suggest that the negative effects of a HF/HFr diet on behavior, brain insulin signaling and Alzheimer-associated changes were alleviated by $\mathrm{CN}$ suggesting that neuroprotective effects of $\mathrm{CN}$ are associated with improved whole body insulin sensitivity and related changes in the brain.
\end{abstract}

Citation: Anderson RA, Qin B, Canini F, Poulet L, Roussel AM (2013) Cinnamon Counteracts the Negative Effects of a High Fat/High Fructose Diet on Behavior, Brain Insulin Signaling and Alzheimer-Associated Changes. PLoS ONE 8(12): e83243. doi:10.1371/journal.pone.0083243

Editor: Josep Bassaganya-Riera, Virginia Tech, United States of America

Received July 8, 2013; Accepted October 22, 2013; Published December 13, 2013

This is an open-access article, free of all copyright, and may be freely reproduced, distributed, transmitted, modified, built upon, or otherwise used by anyone for any lawful purpose. The work is made available under the Creative Commons $\mathrm{CCO}$ public domain dedication.

Funding: The work was funded by USDA/ARS/USA CRADA:58-3K95-7-1184 and French National Agency for Research (PNRA 007). The funders had no role in study design, data collection and analysis, decision to publish, or preparation of the manuscript.

Competing interests: The authors have the following interests: BQ has a joint appointment with the USDA and Integrity Nutraceutical International (Spring Hill, TN). Integrity Nutraceutical International markets a proprietary, patented extract of cinnamon; however, the cinnamon powder used in the current study is not a product of Integrity Neutraceutical International and this study does not involve any products of Integrity. This does not alter the authors' adherence to all the PLOS ONE policies on sharing data and materials.

*E-mail: Richard.anderson@ars.usda.gov

\section{Introduction}

The epidemic of insulin resistance associated with obesity, metabolic syndrome, type 2 diabetes (T2DM), and cardiovascular diseases (CVD) is sweeping both developed and emerging countries. It is estimated that $20-30 \%$ of the adult population in most countries has the metabolic syndrome with some segments of the population even higher [1]. While insulin resistance is a key feature of the metabolic syndrome, it is likely that a similar number of people as those with the metabolic syndrome also have insulin resistance but do not have three of the four features of the metabolic syndrome including central obesity, dyslipidemia, hypertension and elevated blood sugar. The presence of the metabolic syndrome further raises the risk for developing type 2 diabetes by about 5 -fold and persons with the metabolic syndrome are at roughly twice the risk for developing cardiovascular diseases compared with those without the syndrome [1]. Diabetes and cardiovascular complications of insulin resistance are only part of the problem since the insulin resistance syndrome also has consequences on brain function. Increased cognitive alterations are observed in subjects with T2DM and insulin resistance [2-4].

There is a large body of evidence linking impaired insulin function and glucose metabolism to the risk of developing Alzheimer's Disease (AD)-type neurodegeneration [5-8]. Insulin 
resistance has been implicated in the pathogenesis of $A D$ and the term "type 3 diabetes" has been used to describe AD [9]. Experimental brain diabetes produced by intracerebral administration of streptozotocin shares many features with $A D$, including cognitive impairment and disturbances in acetylcholine homeostasis. Experimental brain diabetes is also treatable with insulin sensitizer agents that are used to treat T2DM [9]. AD represents a form of diabetes that selectively involves the brain and has molecular and biochemical features that overlap with both type 1 and T2DM and helps to explain the term type 3 diabetes [9].

Presently there are no known treatments that can stop $A D$, present treatments can only slow the progression of the disease. Due to the link of insulin resistance and AD, factors that slow the progression of insulin resistance should have consequences on $A D$ incidence and rate of progression.

Accumulating studies demonstrating that insulin and insulin signaling mechanisms are important for neuronal survival $[5,7,9]$ and studies demonstrating reduced expression of the insulin receptor and related members of the insulin signaling pathway in patients and animals suffering from impaired brain function and Alzheimer's disease (AD) illustrate the urgent need for further studies involving insulin resistance and the brain.

Diets high in fat and (or) fructose contribute prominently to insulin resistance and impaired cognition. Simple sugars and saturated fats are major components of the diet that promote obesity and insulin resistance. The effects of such diets on the brain are poorly understood but insulin resistance may play an important role by acting on brain energy metabolism and neuroprotective mechanisms. Addition of fructose to the water of rats fed a high-fat, high-glucose diet led to insulin resistance and impaired hippocampal synaptic plasticity and cognition in middle-aged rats [10]. We have shown in in vitro, animal, and human studies that $\mathrm{CN}$, aqueous extracts of $\mathrm{CN}$, and $\mathrm{CN}$ polyphenols not only improve insulin function but also act as antioxidant and anti-inflammatory compounds to counteract the negative effects of insulin resistance and obesity [11-19]. We have also shown that rats fed a high fat/high fructose diet develop insulin resistance that is prevented by addition of $\mathrm{CN}$ to the diet [20].

In this study, we postulated that since $\mathrm{CN}$ improves peripheral insulin sensitivity in animals fed a high fat/high fructose diet [20] and CN also improves insulin signaling in the liver and muscle associated with glycogen synthesis [21], that brain insulin signaling and behavior should also improve. Studies in animal models of impaired insulin sensitivity are needed to further understand the interactions among insulin, neurobiological processes, short-term memory, and cognition.

\section{Materials and Methods}

\section{Cinnamon powder}

The cinnamon (CN) powder (Cinnamomum burmannii) was purchased from McCormick Spice Co., Baltimore, MD. A water extract of the $\mathrm{CN}$ contained more than $5 \%$ type A polyphenols with a tetramer, cassiatannin $A$, with a molecular weight of 1152 and two identified trimers, cinnamtannin B-1 and cinnamtannin D-1, with a molecular weight of 864 plus two unidentified type A trimers with a molecular weight of 864 $[17,22,23]$. The insulin-related bioactivity of the type $A$ polyphenols has been documented [12,16,17,22,24]. The HPLC separation and identification of the selected peaks of the aqueous cinnamon extract has been reported [25].

\section{Animals and diets}

Ethics Statement : All experimental procedures were reviewed and approved by the Institutional Ethic Committee for Animal Care, Research Center of the French Health Service ( IRBA-CRSSA Army Research Center for Health, Grenoble, France) where the animals were housed, (Protocol 2008/02.1). The rats were maintained and handled in accord with the Guide for the Care and Use of Laboratory Rats (NIH, 1985).

Wistar rats (Charles River, L'Arbresle, France), 5 weeks old, were kept in a temperature controlled room (ambient temperature set at $22 \pm 1^{\circ} \mathrm{C}$ and relative humidity at $40-60 \%$ ) with a $12 \mathrm{~h}$ light/12 $\mathrm{h}$ dark cycle (light at $8 \mathrm{~h} 00$ ). The rats were housed in individual cages $(26 \times 40 \times 15 \mathrm{~cm})$ to monitor the water and diet intakes.

The diets were purchased from SAFE (89290, Augis, France). The control diet contained $5 \%$ cellulose, $20 \%$ casein, $25 \%$ corn starch, $25 \%$ potato starch, $16 \%$ maltodextrin, $4 \%$ soybean oil, $3.5 \%$ AIN mineral mix, $1 \%$ AIN vitamin mix, $0.3 \%$ $\mathrm{dl}$ methionine and $0.2 \%$ choline bitartrate. The HF/HFr diet was similar except the corn starch, potato starch and maltodextrin were replaced by $46 \%$ fructose and $20 \%$ lard. The rats were adapted and fed Purina chow (SAFE, Augis, France) for three weeks. They were, then, randomly divided into 4 groups and fed ad libitum for 12 weeks one of the following four diets: Purina chow as the control diet $(\mathrm{C})$, the high fat/high fructose diet (HF/HFr) (described above) to induce insulin resistance, or the respective diets containing $20 \mathrm{~g}$ cinnamon $/ \mathrm{kg}$ of diet $(\mathrm{C}+\mathrm{CN}$ or $\mathrm{HF} / \mathrm{HFr}+\mathrm{CN})$. There were no differences in food intake among the diets. The amount of $\mathrm{CN}$ used was based upon our previous study showing a definite effect of $20 \mathrm{~g}$ of $\mathrm{CN} / \mathrm{kg}$ of diet in spontaneously hypertensive rats [26]. One gram, 3 and 6 grams of CN per day were all shown to have beneficial effects in people with type 2 diabetes [11].

All measurements were performed after 12 weeks of consumption of the diets. In a preliminary investigation, the effects of the diets on insulin resistance were determined in 10 animals of each group using the hyperinsulinemic euglycemic clamp technique [20]. In this investigation based on the same model, the behavioral tests were carried out in 20 animals of each group. The mRNA expression in the hippocampus and cortex (see below) were evaluated in 8 to 10 rats of the 20 rats belonging to each group.

\section{Y-maze}

The Y-maze test evaluates the ability of an animal to recognize places already explored and its propensity to explore a new place [27]. The Y-maze apparatus was made of gray plastic according Dellu's specifications [27]: each arm being $50 \mathrm{~cm}$ long, $16 \mathrm{~cm}$ wide and surrounded by a $32 \mathrm{~cm}$ high wall. The apparatus was placed on a floor generating infrared illumination allowing recording under dim light (25 Lux) to 
reduce anxiety. The $\mathrm{Y}$-maze tests were carried out during the $12^{\text {th }}$ week of diet in a dedicated room. It consisted of two 10min sessions separated by a 2-hour time lapse. In the first session, the rats could explore freely only 2 arms: the arm where they were put (Entry arm) and one (Known arm) of the 2 other arms placed at the left and right of the Entry arm. During the second session, they could explore the entire device, and the new available arm (Unknown arm). Both sessions were done using the same context: same procedure and same environment with spatial cues placed on the walls. The rats were tested in the order of their randomization rank. However, each group was equally represented in the tests made in the morning $(8 \mathrm{~h}-12 \mathrm{~h})$ or the afternoon $(13 \mathrm{~h}-17 \mathrm{~h})$ or according to the initial condition, namely the left or right arm occlusion during the first session.

For testing, the rats were transferred from the home room to the testing room in their own cage without being handled. They were gently placed at the end of the entry arm of the Y-maze, the nose being directed to the wall. The experimenter left the rat alone in the room and launched immediately the video recording using a remote control device. At the end of the session, the number of defecation bolus was counted. Meticulous clean ups were then completed, one with soapy water and one with water/isopropyl alcohol (50\%) solution. The behavior was recorded on a computer, locomotion being automatically analyzed using a video tracking device (Videotrack, Viewpoint, Lyon) and rearings being scored by the experimenter (Labwatcher, Viewpoint, Lyon). The global behavior in the test was assessed using (i) the defecation bolus number, (ii) the distance traveled in the whole Y-maze, (iii) the time spent in rearing and, (iv) the percentage of spontaneous choices of the unknown arm in the second session (alternation). The cognitive aspect of the behavior was analyzed on the first 2-min of the Y-maze exposure. The variables used were the number of entries, the distance traveled and the time spent in each of the 3 arms. The entry in a given arm was considered when the rat went beyond the initial $10 \mathrm{~cm}$ of the arms.

\section{The Elevated-Plus-Maze}

The Elevated-Plus-Maze (EPM) test evaluates mainly the anxiety level of rats[27]. It was carried out 2 days after the $Y$ maze in the same room. The EPM apparatus is a cross with 4 arms of $50 \mathrm{~cm}$ long and $10 \mathrm{~cm}$ wide, two arms are surrounded by a $40 \mathrm{~cm}$ high wall (closed arms) whereas the 2 others are deprived from wall (open arms). The device, transparent for infrared illumination, was placed above the infrared floor. The open arms were largely illuminated (450 Lux) but the closed arms were in a dim light (60 Lux).

The rats were transferred from housing facilities to the testing room in their own cage. They were placed at the center of the cross, the nose oriented to the closed arms, and left for a 10-min free exploration. At the end, the number of defecations was counted and the apparatus carefully cleaned with soapy water and then a water/isopropyl alcohol (50\%) solution.

The behavior was recorded using the same videotracking system (Viewpoint, Lyon). The variables considered over the entire test duration were the following (i) the defecation bolus number, (ii) the number of entries in open and closed arms, (iii) the distance traveled in closed arms and (iv) the time spent in open arms.

\section{Sacrifice and tissue sampling}

The rats were sacrificed in the morning after overnight fasting. They were transferred in their home cage to a dedicated room to avoid any additive stress. They were quickly anesthetized with a mixture of isofluran $\left(3 \%\right.$ in $\left.100 \% \mathrm{O}_{2}\right)$. Blood samples were taken by cardiac puncture in a tube coated with lithium heparinate or EDTA. The brain was quickly removed and dissected on an ice bed using a glass tool. The entire hippocampus and the frontal cortex were sampled and immediately frozen in liquid nitrogen and stored at $-80^{\circ} \mathrm{C}$ until analyses.

\section{mRNA determinations}

Total RNA was isolated from hippocampus and cortex using Trizol reagent (Invitrogen, Carlsbad, CA). RNA concentrations and integrity were determined using RNA 6000 Nano Assay Kit and the Bioanalyzer 2100 according to the manufacturer's instructions (Agilent Technologies, Santa Clara, CA). The primers used for $\mathrm{PCR}$ were as follows: Ir primers, 5'CAAAAGCACAATCAGAGTGAGTATGAC-3' and 5'ACCACGTTGTGCAGGTAATCC-3'; Irs1 primers, 5'GCCTGGAGTATTATGAGA ACGAGAA-3' and 5'GGGGATCGAGCGTTTGG-3'; Irs2 primers, 5'AAGATAGCGGGTACATGCGAAT -3' and 5'GCAGCTTAGGGTCTGGGTTCT -3'; Glut1 primers, 5'GTGCTTATGGGTTTCTCCAAA-3' and 5'GACACCTCCCCCACATACATG -3'; Glut2 primers, 5'TTTGCAGTAGGCGGAATGG-3' and 5'GCCAACATGGCTTTGATCCTT-3'; Gys1 primers, 5'TCCACTGTGCCTGTGTCTTCA-3' and 5'AGAGAACTTCTTCACATTCAGTCCATT-3'; Gsk3b primers, 5'TTAAGGAAGGAAAAGGTGAATCGA-3' and 5'CCAAAAGCTGAAGGCTGCTG-3'; $18 \mathrm{~S}$ primers, 5'TAAGTCCCTGCCCTTTGTACACA-3' and 5'ATCCGAGGGCCTCACTA

AAC-3'. mRNA levels were assessed by real-time quantitative RT-PCR. All PCR reactions were performed in a total volume of $25 \mu \mathrm{l}$ and included the following components: cDNA derived from $25 \mathrm{ng}$ of total RNA, $400 \mathrm{nM}$ of each primer, RNase-free water, and $12.5 \mu$ l of SYBR Green PCR Master Mix $(A B I)$, an optimized buffer system containing AmpliTaq Gold DNA polymerase and dNTPs. All PCR reactions were performed in duplicate and cycling parameters were as follows: after an initial denaturation step for $10 \mathrm{~min}$ at $95^{\circ} \mathrm{C}, 40$ subsequent cycles were performed in which samples were denatured for $15 \mathrm{~s}$ at $95^{\circ} \mathrm{C}$ followed by primer annealing and elongation at $60^{\circ} \mathrm{C}$ for $1 \mathrm{~min}$. The relative quantities of mRNA were normalized by $18 \mathrm{~S}$ rRNA content.

\section{Statistical analyses}

Data are expressed as means $\pm \mathrm{SE}$. For the behavior testing, the statistical analyses were done using Statistica 7.1 software (Statsoft). The effect of conditioning was analyzed using a two-way factorial analysis with the Diet (High Fat/High 
Table 1. Behavioral performance in Y-maze.

\begin{tabular}{|c|c|c|c|c|c|}
\hline & & C & $\mathrm{C}+\mathrm{CN}$ & $\mathrm{HF} / \mathrm{HFr}$ & $\mathrm{HF} / \mathrm{HFr}+\mathrm{CN}$ \\
\hline & & Mean SE & Mean SE & Mean SE & Mean SE \\
\hline \multirow[t]{2}{*}{ Defecation } & Session 1 & $1.7 \pm 0.5$ & $1.2 \pm 0.4$ & $1.9 \pm 0.6$ & $2.5 \pm 0.7$ \\
\hline & Session 2 & $0.7 \pm 0.3$ & $0.6 \pm 0.3$ & $0.7 \pm 0.3$ & $1.1 \pm 0.3$ \\
\hline \multirow[t]{2}{*}{ Distance } & Session 1 & $2209 \pm 151$ & $2825 \pm 128$ & $2467 \pm 144$ & $2485 \pm 114 \#$ \\
\hline & Session 2 & $2417 \pm 174$ & $3180 \pm 200$ & $2501 \pm 254$ & $2822 \pm 139 \#$ \\
\hline \multirow[t]{2}{*}{ Rearing duration } & Session 1 & $94 \pm 9$ & $122 \pm 9$ & $100 \pm 10$ & $113 \pm 13$ \\
\hline & Session 2 & $102 \pm 11$ & $156 \pm 11$ & $111 \pm 14$ & $130 \pm 10 \# \#$ \\
\hline
\end{tabular}

Behavioral data were obtained during the entire $\mathrm{Y}$-maze test (sessions1 and 2) in Control $(\mathrm{C})$, control plus cinnamon $(\mathrm{C}+\mathrm{CN})$, high fat/high fructose $(\mathrm{HF} / \mathrm{HFr})$ and high fat/high fructose diet plus cinnamon $(\mathrm{HF} / \mathrm{HFr}+\mathrm{CN})$. There were 20 rats per group. Defecation, distance traveled $(\mathrm{cm})$ and duration of rearing $(\mathrm{sec})$ are expressed as mean $\pm \mathrm{SE}$. Comparisons among groups were done using 2-way factorial ANOVA with cinnamon effect ( ${ }^{\#} \mathrm{P}<0.05$ and $\left.{ }^{\# \#} \mathrm{P}<0.01\right)$

doi: 10.1371/journal.pone.0083243.t001

Fructose vs. Control Diet) and the CN (Cinnamon vs. NoCinnamon) effects and interactions. If necessary, post-hoc tests were carried out using the Bonferroni test for all couples. Differences in performance from one to another of Y-maze sessions were assessed using analysis of variance for repeated measurements. Differences in alternance rate were analyzed using $\mathrm{Chi}^{2}$ test. One-way analysis of variance (ANOVA) was used to determine the significance of the effects of diet and $\mathrm{CN}$ treatment on mRNA. When significant intergroup differences were found $(P<0.05)$, the Tukey's test was carried out. Different superscripts indicate significant differences among groups, $\mathrm{P}<0.05$.

\section{Results}

In an associated study, we demonstrated that the animals fed the HF/HFr diet had decreased insulin sensitivity based upon the hyperinsulinemic euglycemic clamp procedure and that $\mathrm{CN}$ prevented the negative effects of the HF/HFr diet on insulin sensitivity [20].

\section{Y-maze}

In this study, no difference in defecation number was observed among groups in either of the 2 sessions (Table 1 ). In the first session, CN supplementation was followed by an enhanced motor activity as suggested by the increase in distance traveled $(P<0.05)$ and time spent in rearing. The same was observed in the second session (distance traveled, $P<0.01$ and rearing duration, $P<0.01$ ). A habituation to the device occurred in each group as the rats exhibited less defecation number, greater distance traveled and more time spent in rearing (session 1 vs. session 2, $\mathrm{P}<0.05$ for each variable in each group).

No differences among groups were observed in their propensity to choose the Unknown arm at the beginning of the second session of $\mathrm{Y}$-maze: $\mathrm{C}: 18$ out of 20 rats, $\mathrm{C}+\mathrm{CN}$ : 14 out of 20 rats, HF/HFr: 16 out of 20 rats and $\mathrm{HF} / \mathrm{HFr}+\mathrm{CN}$ : 15 out of
20 rats. Each group exhibited a performance far above random (at least $\mathrm{P}<0.05$ for each group).

The activating effect of $\mathrm{CN}$ was also observed in the first 2min period of the first session as $\mathrm{CN}$ rats had an increased distance traveled (Entry arm, $\mathrm{P}<0.05$ ) (Table 2). This was also observed in the first 2-min period of the second session: $\mathrm{CN}$ rats exhibited an increased number of entries (Entry arm, $\mathrm{P}<0.05$ and Known arm, $\mathrm{P}<0.05)$ and distance traveled $($ Known arm, $\mathrm{P}<0.01)$. The $\mathrm{CN}$ rats also presented an increased time spent in the Entry arm $(P<0.05)$. No differences in interest for the Unknown arm were observed among groups: same number of entries, same time spent and distance traveled inside. Differences between the 2 sessions were observed differently according to groups. The $\mathrm{C}$ rats had reduced exploration of the Known arm (number of entries, $\mathrm{P}<0.001$; time spent, $\mathrm{P}<0.05$ and distance traveled, $\mathrm{P}<0.001)$. The $\mathrm{C}+\mathrm{CN}$ rats had reduced exploration of both the Entry arm (number of entries, $\mathrm{P}<0.05$; time spent, $P<0.01$ and distance traveled, $P<0.001)$ and the Known arm (number of entries, $P<0.01$ and time spent, $P<0.01$ ). The $H F / H F r$ rats limited their interactions with the Entry arm (number of entries, $\mathrm{P}<0.05$ and distance traveled, $\mathrm{P}<0.001$ ) and the Known arm (time spent, $\mathrm{P}<0.05$ and distance traveled, $\mathrm{P}<0.01)$. The $\mathrm{HF} / \mathrm{HFr}+\mathrm{CN}$ rats only reduced their interaction with the Entry arm (time spent, $\mathrm{P}<0.01$ and distance traveled, $\mathrm{P}<0.001$ ).

\section{Elevated-plus-maze}

The rats having $\mathrm{CN}$ supplementation had higher defecation number than the rats fed without $C N(p<0.05)$ (Table 3$)$. The rats fed with $\mathrm{HF} / \mathrm{HFr}$ entered less $(p<0.05)$, spent less time $(p<0.05)$ and carried out less locomotion $(p<0.05)$ in the open arms than the rats fed with $C$ diet. No differences of locomotion, number of entries and time spent were observed among groups in the closed arms.

\section{mRNA effects}

Consistent with the negative effects of the HF/HFr diet on insulin sensitivity, and behavior, there were also decreases in mRNA for glucose transporters in the hippocampus and cortex. Animals consuming the HF/HFr diet had a decrease in mRNA coding for GLUT1, the principal glucose transporter of the blood-brain barrier, in both the hippocampus and cortex that was prevented by the CN (Figure 1, left panel). mRNA coding for GLUT3, the main facilitative glucose transporter in neurons, was also decreased by the HF/HFr diet in the cortex with a return to the level of the control diet in the animals consuming the control diet plus CN (Figure 1, right panel).

Contrary to that observed in the muscle [21], consumption of the HF/HFr diet led to increases in insulin receptor (Ir), Irs1 and 2 in the hippocampus and cortex that were not reversed by $\mathrm{CN}$ (Figure 2) demonstrating that changes in these variables in the hippocampus and cortex were not associated with similar changes in the periphery. Associated negative effects on these variables related to insulin resistance requires further study.

There were significant effects due to $\mathrm{CN}$ on the mRNA coding for glycogen synthase, Gys1, in animals consuming both the control diet as well as those consuming the HF/HFr diet in both the hippocampus and cortex (Figure 3, left panel). 
Table 2. Behavioral performance in Y-maze.

\begin{tabular}{|c|c|c|c|c|c|}
\hline & & C & $\mathrm{C}+\mathrm{CN}$ & $\mathrm{HF} / \mathrm{HFr}$ & $\mathrm{HF} / \mathrm{HFr}+\mathrm{CN}$ \\
\hline Entry arm & & Mean SE & Mean SE & Mean SE & Mean SE \\
\hline \multirow{2}{*}{$\begin{array}{l}\text { Number of } \\
\text { entries }\end{array}$} & Session1 & $2.50 \pm 0.24$ & $3.15 \pm 0.20$ & $2.8 \pm 0.17$ & $2.80 \pm 0.25$ \\
\hline & Session 2 & $2.15 \pm 0.17$ & $2.55 \pm 0.17^{a}$ & $2.15 \pm 0.15^{a}$ & $2.50 \pm 0.17^{\#}$ \\
\hline \multirow[t]{2}{*}{ Time spent } & Session 1 & $54 \pm 6$ & $54 \pm 5$ & $59 \pm 5$ & $67 \pm 6$ \\
\hline & Session 2 & $50 \pm 7$ & $27 \pm 3^{b}$ & $47 \pm 7$ & $40 \pm 6^{\# b}$ \\
\hline \multirow[t]{2}{*}{$\begin{array}{l}\text { Distance } \\
\text { traveled }\end{array}$} & Session 1 & $190 \pm 18$ & $247 \pm 13$ & $227 \pm 14$ & $234 \pm 13^{\#}$ \\
\hline & Session 2 & $155 \pm 13$ & $164 \pm 16^{c}$ & $158 \pm 9^{c}$ & $159 \pm 11^{c}$ \\
\hline \multicolumn{6}{|l|}{ Known arm } \\
\hline \multirow[t]{2}{*}{$\begin{array}{l}\text { Number of } \\
\text { entries }\end{array}$} & Session 1 & $1.75 \pm 0.22$ & $2.40 \pm 0.23$ & $1.85 \pm 0.2$ & $2.00 \pm 0.25$ \\
\hline & Session 2 & $1.00 \pm 0.13^{c}$ & $1.75 \pm 0.19^{b}$ & $1.5 \pm 0.28$ & $1.70 \pm 0.23$ \# \\
\hline \multirow[t]{2}{*}{ Time spent } & Session 1 & $40 \pm 6$ & $35 \pm 3$ & $30 \pm 4$ & $31 \pm 5$ \\
\hline & Session 2 & $22 \pm 7^{a}$ & $28 \pm 5^{b}$ & $18 \pm 3^{a}$ & $21 \pm 3$ \\
\hline \multirow[t]{2}{*}{$\begin{array}{l}\text { Distance } \\
\text { traveled }\end{array}$} & Session 1 & $157 \pm 14$ & $193 \pm 17$ & $149 \pm 13$ & $143 \pm 16$ \\
\hline & Session 2 & $81 \pm 11^{c}$ & $142 \pm 13$ & $100 \pm 17^{b}$ & $117 \pm 15^{\# \#}$ \\
\hline \multicolumn{6}{|c|}{ Unknown arm } \\
\hline $\begin{array}{l}\text { Number of } \\
\text { entries }\end{array}$ & Session 2 & $2.45 \pm 0.34$ & $3.00 \pm 0.28$ & $2.2 \pm 0.24$ & $2.50 \pm 0.29$ \\
\hline Time spent & Session 2 & $24 \pm 3$ & $30 \pm 4$ & $25 \pm 3$ & $24 \pm 3$ \\
\hline $\begin{array}{l}\text { Distance } \\
\text { traveled }\end{array}$ & Session 2 & $164 \pm 21$ & $202 \pm 15$ & $160 \pm 18$ & $169 \pm 19$ \\
\hline \multicolumn{6}{|c|}{$\begin{array}{l}\text { Behavioral data were obtained during the first } 120 \text { sec of } \mathrm{Y} \text {-maze test (session } 1 \\
\text { and } 2) \text { in Control }(\mathrm{C}) \text {, control plus cinnamon }(\mathrm{C}+\mathrm{CN}) \text {, high fat/high fructose }(\mathrm{HF} / \\
\mathrm{HFr}) \text { and high fat/high fructose diet plus cinnamon }(\mathrm{HF} / \mathrm{HFr}+\mathrm{CN}) \text { groups. There } \\
\text { were } 20 \text { rats per group. Number of entries, the time spent }(\mathrm{sec}) \text { and distance } \\
\text { traveled }(\mathrm{cm}) \text { in each of the } 3 \text { arms are expressed as mean } \pm \mathrm{SE} \text {. Comparisons } \\
\text { among groups were done using } 2 \text {-way factorial ANOVA with cinnamon effect } \\
\left(\#^{\#}<0.05 \text { and }{ }^{\# \#<0.01) . ~ C o m p a r i s o n ~ b e t w e e n ~ s e s s i o n s ~ w e r e ~ d o n e ~ i n ~ e a c h ~ g r o u p ~}\right. \\
\left.\text { using ANOVA for repeated measurements ( }{ }^{a} \mathrm{P}<0.05 ;{ }^{b}<0.01 ;{ }^{c} \mathrm{P}<0.001\right) \\
\text { doi: } 10.1371 \text { journal.pone.0083243.t002 }\end{array}$} \\
\hline
\end{tabular}

Changes in the mRNA coding for glycogen synthase kinase (GSK-3ß), which is involved in the control of the activity of glycogen synthase, were increased in animals consuming the $\mathrm{HF} / \mathrm{HFr}$ diet and not altered by $\mathrm{CN}$ in animals consuming either the control or HF/HFr diet in either the hippocampus or cortex (Figure 3, middle panel). Increases in mRNA coding for protein kinase $B$ (AKT1), a key control step in insulin signaling, were significant in animals consuming the HF/HFr diet plus $\mathrm{CN}$ in the hippocampus but not the cortex (Figure 3, right panel).

The negative effects of the HF/HFr diet on insulin sensitivity were associated with negative effects on mRNA coding for proteins associated with Alzheimer's disease and memory loss including phosphatase and tensin homolog (Pten), Tau and amyloid precursor protein (App) (Figure 4). The HF/HFr diet led to increases in Pten (Figure 4, left panel), Tau (Figure 4, middle panel) and App (Figure 4, right panel) that were reversed by $\mathrm{CN}$. Increases in these variables are associated with decreased insulin sensitivity. Cinnamon had no detectable significant effects on these variables in animals consuming the
Table 3. Behavioral performance in Elevated Plus Maze test.

\begin{tabular}{|c|c|c|c|c|}
\hline Diet & C & $\mathrm{C}+\mathrm{CN}$ & $\mathrm{HF} / \mathrm{HFr}$ & $\mathrm{HF} / \mathrm{HFr}+\mathrm{CN}$ \\
\hline & Mean SE & Mean SE & Mean SE & Mean SE \\
\hline Defecations & $0.6 \pm 0.3$ & $2.1 \pm 0.6$ & $0.8 \pm 0.4$ & $1.6 \pm 0.4 \#$ \\
\hline \multicolumn{5}{|l|}{ Open arms } \\
\hline Entries & $6.9 \pm 1.3$ & $6.9 \pm 0.9$ & $4.4 \pm 0.7$ * & $5.3 \pm 0.7$ \\
\hline Time spent & $70 \pm 17$ & $67 \pm 11$ & $36 \pm 8$ * & $43 \pm 8$ \\
\hline Distance & $416 \pm 108$ & $410 \pm 63$ & $211 \pm 50$ * & $256 \pm 42$ \\
\hline \multicolumn{5}{|l|}{ Closed arms } \\
\hline Entries & $17.8 \pm 1.5$ & $17.7 \pm 0.9$ & $13.9 \pm 1.7$ & $18.7 \pm 1.7$ \\
\hline Time spent & $465 \pm 23$ & $480 \pm 15$ & $515 \pm 14$ & $493 \pm 12$ \\
\hline Distance & $1811 \pm 74$ & $1860 \pm 87$ & $1782 \pm 134$ & $1948 \pm 114$ \\
\hline \multicolumn{5}{|c|}{$\begin{array}{l}\text { Behavioral data obtained during Elevated-Plus Maze test in Control }(\mathrm{C}) \text {, control } \\
\text { plus cinnamon }(\mathrm{C}+\mathrm{CN}) \text {, high fat/high fructose diet }(\mathrm{HF} / \mathrm{HFr}) \text { and high fat/high } \\
\text { fructose diet plus cinnamon }(\mathrm{HF} / \mathrm{HFr}+\mathrm{CN}) \text { groups. Number of defecations in the } \\
\text { entire device, the number of entries, and the time spent }(\mathrm{sec}) \text { and distance traveled } \\
\text { ( } \mathrm{cm}) \text { in the open and closed arms are expressed as mean } \pm \mathrm{SE} \text {. Comparisons } \\
\text { were done using 2-way factorial ANOVA with diet effect }\left({ }^{*} \mathrm{P}<0.05\right) \text { and cinnamon } \\
\text { effect (\# } \mathrm{P}<0.05) \text {. } \\
\text { doi: } 10.1371 / \text { journal.pone. } 0083243 . t 003\end{array}$} \\
\hline
\end{tabular}

control diet. There were no detectable effects of $\mathrm{CN}$ on the animals consuming the control diet plus $\mathrm{CN}$.

\section{Discussion}

Cinnamon is often used to refer to Ceylon cinnamon or "true cinnamon" (Cinnamomum verum) however, related species of cassia (C. aromaticum and C. burmannii) are often sold as $\mathrm{CN}$. Cinnamon was first imported to Egypt in $2000 \mathrm{BC}$ and it is often referred to in the bible [19]. While the taste and coumarin content often differ substantially among cinnamons, many of the properties and effects of the true $\mathrm{CN}$ and related species are similar. Cinnamon has a long history of uses as a spice, flavoring agent, preservative, and pharmacological agent. More recent studies have documented the role of $\mathrm{CN}$ in the prevention of insulin resistance, metabolic syndrome and type 2 diabetes (see review) [19]. In addition, CN has been shown to alleviate factors associated with Alzheimer's disease and memory loss by blocking and reversing TAU formation and blocking the effects of amyloid precursor protein [28]. The common link between Alzheimer-like changes and type 2 diabetes may be insulin resistance. The peripheral insulinsensitizer drug, metformin, ameliorates neuronal insulin resistance and Alzheimer-like changes [5]. Evidence that insulin signaling mechanisms are important for neuronal survival $[9,29]$ and studies demonstrating reduced expression of the insulin receptor in the brain of patients suffering from $A D$ have generated increased interest in determining the role of impaired insulin actions associated with Alzheimer-like changes [5]. The fact that insulin receptors are widely expressed in the brain, combined with the observation that insulin crosses the blood-brain barrier by a saturable, receptor mediated transport mechanism, further highlights the observations that insulin likely plays a key role in memory and 


\section{Hippocampus/Glut1}

\section{Hippocampus/Glut3}

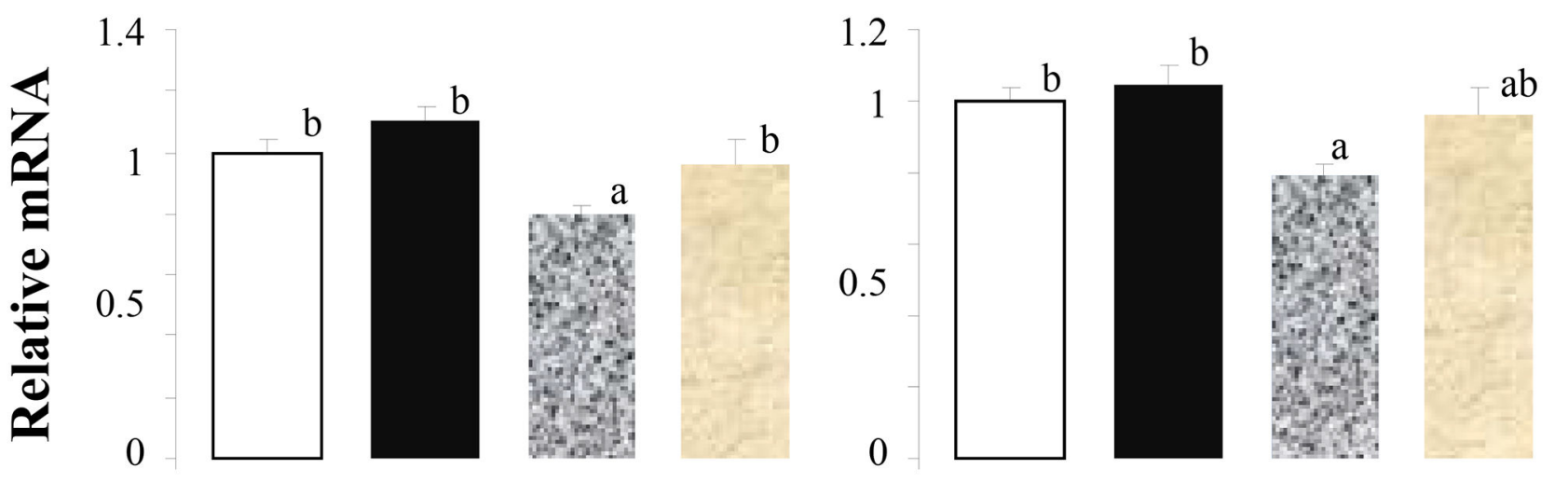

\section{Cortex/Glut1}

\section{Cortex/Glut3}
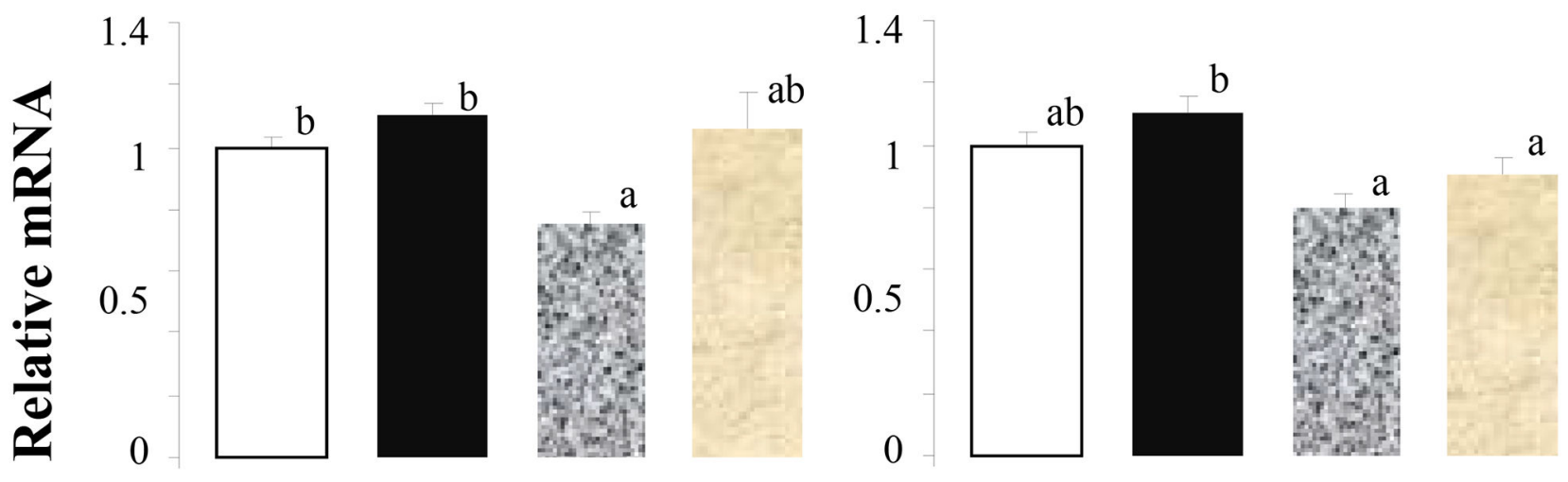

Figure 1. High Fat/High Fructose (HF/HFr) diet decreases Glut 1 and 3 in hippocampus and cortex. Open bar, control diet; solid bar, control diet plus cinnamon, mottled gray bar, HF/HFr diet; gray bar, HF/HFr diet plus cinnamon. Values are mean \pm SE for 8 to 10 rats. Different letters denote significant differences among groups, $p<0.05$.

doi: 10.1371/journal.pone.0083243.g001

cognition [30,31]. Defective insulin signaling is associated with decreased cognitive ability and development of dementia. Neurons are insulin-dependent metabolically active tissues, like fat and muscle, that develop insulin resistance and thus cannot respond properly to the neurotrophic properties of insulin, resulting in neuronal injury, subsequent dysfunction and ultimately Alzheimer's and related diseases [32].

Impaired insulin sensitivity, measured by HOMA, is associated with deficits in verbal fluency [33] and it is not necessary to wait to have overt signs of $A D$ to detect changes in behavior, memory and cognition. Short-term memory alteration has been found in the early phases of $A D$ [34] and in diets high in fat [35]. In addition, HbA1c is associated with executive functioning and working memory in people with insulin resistance [36] and $\mathrm{CN}$ also improves $\mathrm{HbA1c}$ [37-39].

In this study, we measured the effects of early changes in insulin sensitivity and the counteracting insulin sensitizing effects of $\mathrm{CN}$, on changes in behavior and mRNA associated with insulin signaling and Alzheimer's. The HF/HFr diet is known to induce changes in behavior [40,41], memory and cognition [42,43]. In our study, the HF/HFr did not induce changes in short-term memory as detected using the $\mathrm{Y}$-maze. Animals fed with HF/HFr diet exhibited the same probability as rats fed with the control chow diet of spontaneous choice of unexplored arm in the second session of Y-maze. Further, they showed the same level of habituation to testing conditions as suggested by the decrease in defecation number and the enhanced locomotion in the second session compared to the first one.

In the elevated plus maze, the HF/HFr fed rats exhibited decreased exploration of the open arm. The reduced exploration of open arms cannot be explained by a decrease in locomotion since the explorations of closed arms were not different among groups. It would be better explained by an 


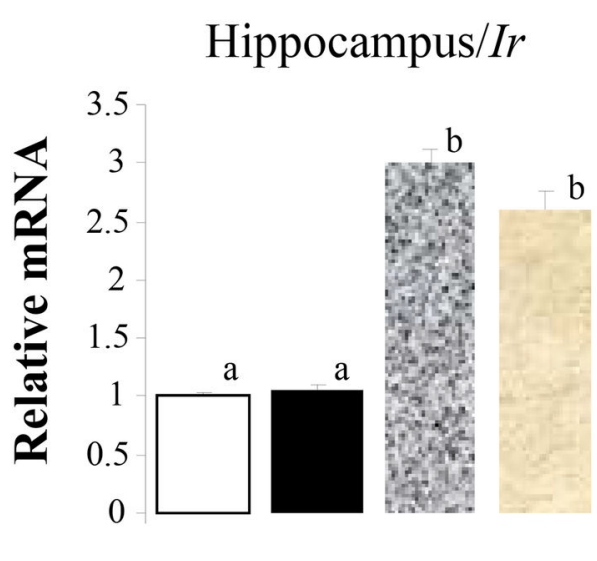

Cortex/Ir
Hippocampus/Irs 1

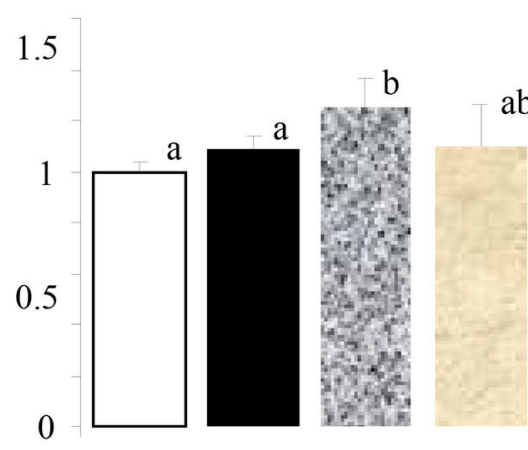

Hippocampus/Irs2

1.8

ab 1.5
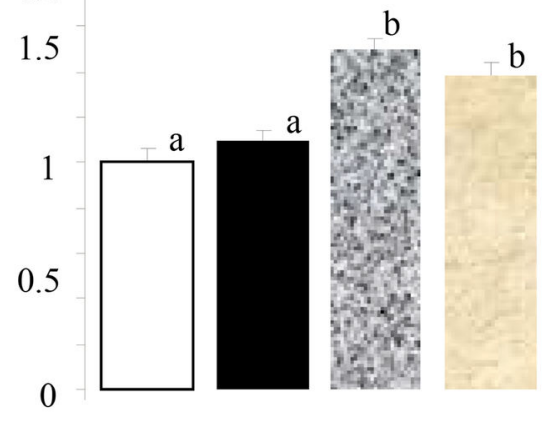

Cortex/Irs 1

Cortex/Irs2

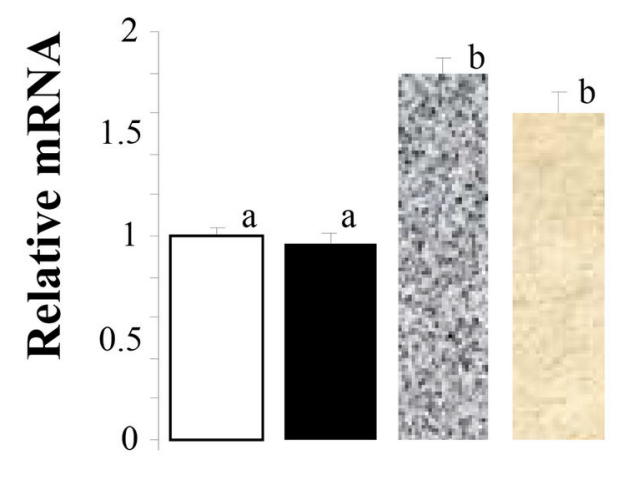

1.4

b

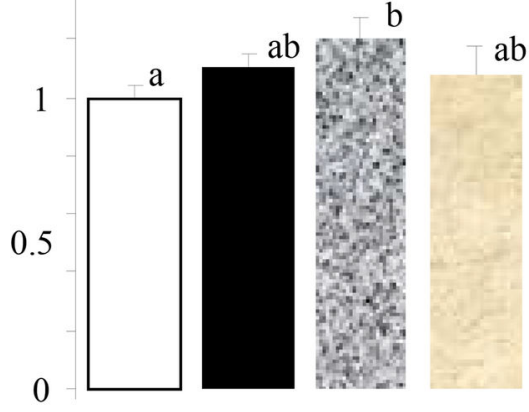

1.5

$\mathrm{ab}$

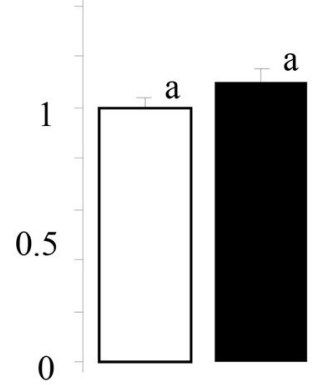

b

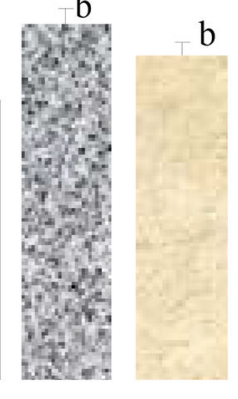

Figure 2. High Fat/High Fructose diet increases Insr, Irs1 and Irs2 in hippocampus and cortex. Open bar, control diet; solid bar, control diet plus cinnamon, mottled gray bar, HF/HFr diet; gray bar, HF/HFr diet plus cinnamon. Values are mean \pm SE for 8 to 10 rats. Different letters denote significant differences among groups, $p<0.05$.

doi: 10.1371/journal.pone.0083243.g002

enhanced anxiety level [44]. The effect of HF/HFr on anxiety is congruent to the anxiogenic effect of a diet rich in sucrose [45] and with increased stress reactivity induced by a HF diet [46]. However, the latter effect is not always observed, especially in case of a short term HF diet [47]. The anxiety level of HF/HFr rats seems context-dependent as it was observed in EPM but not in Y-maze when HF/HFr rats coped with the Unknown arm during the second session. The differences between both behaviors may be related to the level of aggressiveness as $\mathrm{Y}$ maze Unknown arm is more secure than the open arm of EPM due to the wall and the dim light.

The HF/HFr diet used in this study has been shown to induce an impairment of insulin-sensitivity in muscle and liver [21]. We also observed brain mRNA expression alterations indicative of insulin resistance in this study (Figures 1-4). Such alterations might have behavioral counterparts. Since insulin crosses the blood-brain barrier by a saturable, receptor mediated transport mechanism and acts on receptors widely expressed in the brain [48], it may modulate brain functions such as memory and cognition $[30,31,49]$. Impaired insulin sensitivity would be one relevant hypothesis to explain $\mathrm{HF} / \mathrm{HFr}$ diet-induced behavioral alterations. In humans, impaired insulin sensitivity, as measured by HOMA score, is associated with deficits in verbal fluency [33] and intranasal insulin increases verbal memory in humans [50]. HbA1c is associated with executive functioning and working memory in people with insulin resistance [36]. In animals, impaired insulin-sensitivity is also associated with behavioral perturbations [40,42,45] while intracerebroventricular insulin increases memory in rodents [51]. The hippocampus is one of the potential targeted brain areas, as insulin receptors are found at high densities [31]. Furthermore, the hippocampus inhibits stress reaction and supports explicit and spatial memory [33]; all functions being modulated by insulin effects. One hypothesis would be that insulin resistance in hippocampus might explain the enhanced anxiety. Alternatively, the frontal cortex would be also questioned as insulin receptors are also highly expressed [48] and working memory is impaired in case of insulin resistance [36]. This is in agreement with the fact that insulin sensitivity is also impaired in frontal cortex area.

The mechanisms by which insulin sensitivity may act on brain deserve discussion. Brain is an insulin-dependent 


\section{Hippocampus/Gys 1 Hippocampus/Gsk3b Hippocampus/Akt1}

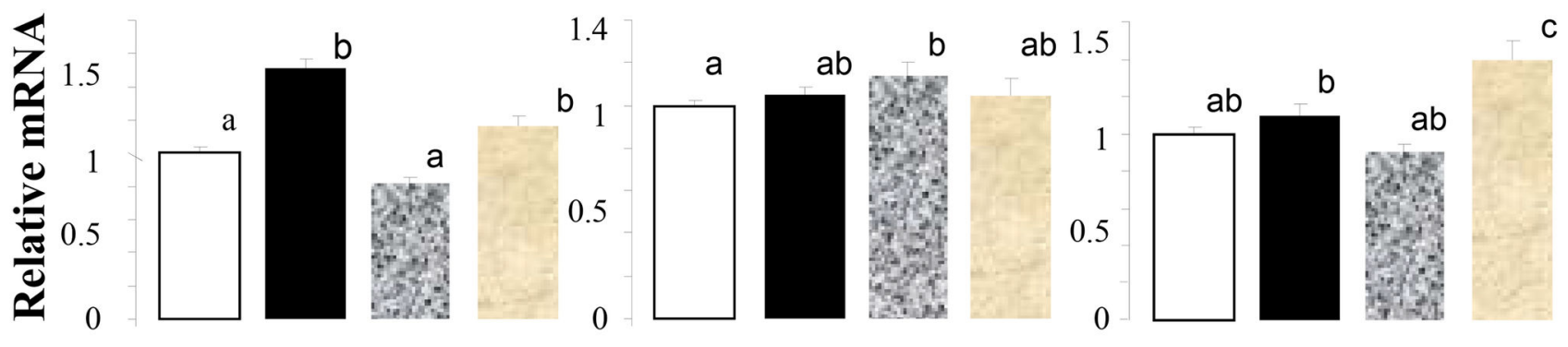

Cortex/Gys 1

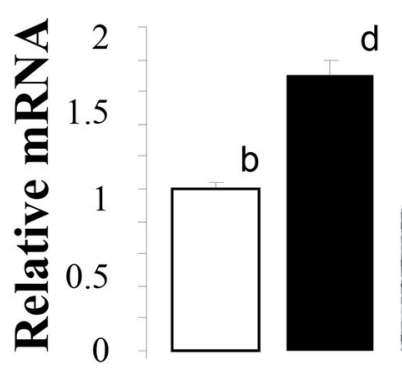

Cortex/Gsk3b

\section{Cortex/Akt1}

Figure 3. High Fat/High Fructose diet effects on Gys1, Gsk3 $\beta$ and Akt1 in hippocampus and cortex. Open bar, control diet; solid bar, control diet plus cinnamon, mottled gray bar, HF/HFr diet; gray bar, HF/HFr diet plus cinnamon. Values are mean \pm SE for 8 to 10 rats. Different letters denote significant differences among groups, $p<0.05$.

doi: 10.1371/journal.pone.0083243.g003

metabolically active tissue, like fat and muscle. Insulin may therefore act through its metabolic effects. The exposure to a challenging environment is associated with brain activation during which an increase in breakdown of glycogen occurs [52]. The rapid increase in glycogen turnover appears important for memory formation as supported by the memory loss after inhibition of glycogen turnover [53]. Insulin, which favors glycogen turnover [54] and improves memory [48,51], may therefore act on brain function through its metabolic effects. The same can be concluded for frontal cortex as insulin increases working memory [55]. Decreases in insulin sensitivity were associated with the anticipated decreases in Glut 1, in both the hippocampus and cortex. GLUT1 is highly expressed in endothelial cells of blood brain barrier and is responsible for transporting glucose from the blood to extracellular space of the brain [56]. Alternatively, insulin may act through its effect on neurotrophicity $[7,48]$. There is evidence that insulin signaling mechanisms are important for neuronal survival $[9,29]$. In the case of insulin resistance, the brain cannot respond properly to the neurotrophic properties of insulin, resulting in neuronal injury, subsequent dysfunction and ultimately Alzheimer's and related diseases [32].
We observed several mRNA expression changes supporting the hypothesis that insulin resistance might be associated with the occurrence of $A D$ brain markers. The increase in TAU filaments is associated with extensive deposition of amyloid $\beta$ and a strong association with AD. The amyloid $\beta$ hypothesis states that amyloid $\beta$ deposition directly affects neurons, including neurofibrillary tangles and neuronal death, leading to memory impairment which is one of the key clinical signs of AD-related brain dysfunction. Mice engineered to over express mutant APP exhibit increased APP deposition and memory impairment [57]. However, reducing amyloid $\beta$ generation or removing deposits failed to halt the progression of dementia $[58,59]$. Consistent with these studies, we observed an increase in mRNA coding for TAU and APP in both hippocampus and frontal cortex. GSK-3 $\beta$ intervenes before neurofibrillary tangles are formed since GSK-3 $\beta$ phosphorylates TAU protein, a step leading to granular TAU oligomers, then neuronal dysfunction and synaptic loss [58].

Recent studies have documented the role of $\mathrm{CN}$ in the prevention of insulin resistance, metabolic syndrome and type 2 diabetes (see review) [19]. CN also inhibits the misfolding of human islet amyloid polypeptide which is regarded as a causative factor for type 2 diabetes mellitus [60]. CN 


\section{Hippocampus/Pten}

Hippocampus/Tau

Hippocampus/App

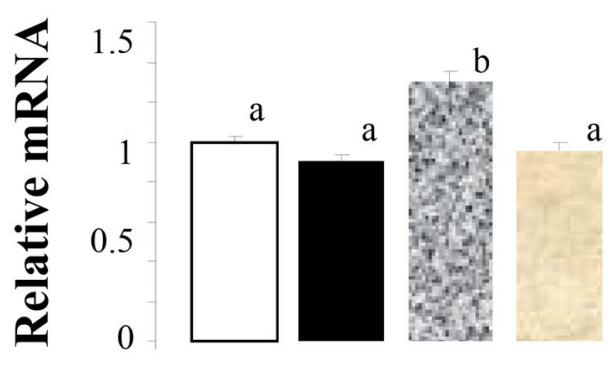

Cortex/Pten

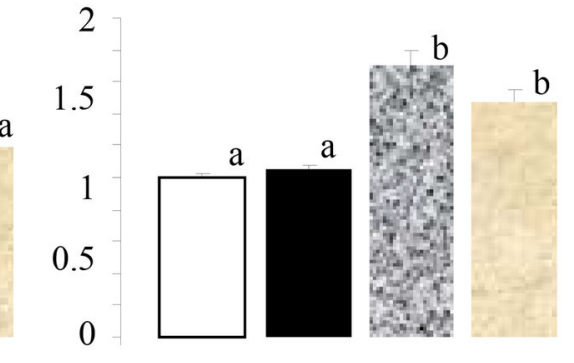

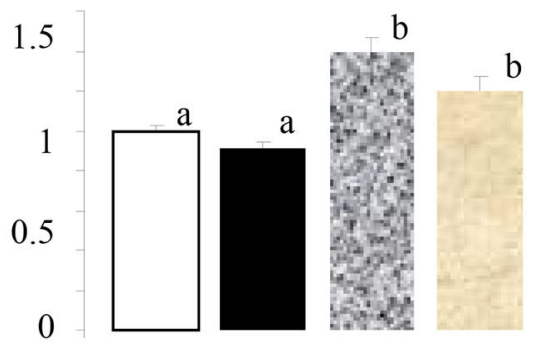

Cortex/Tau

Cortex/App
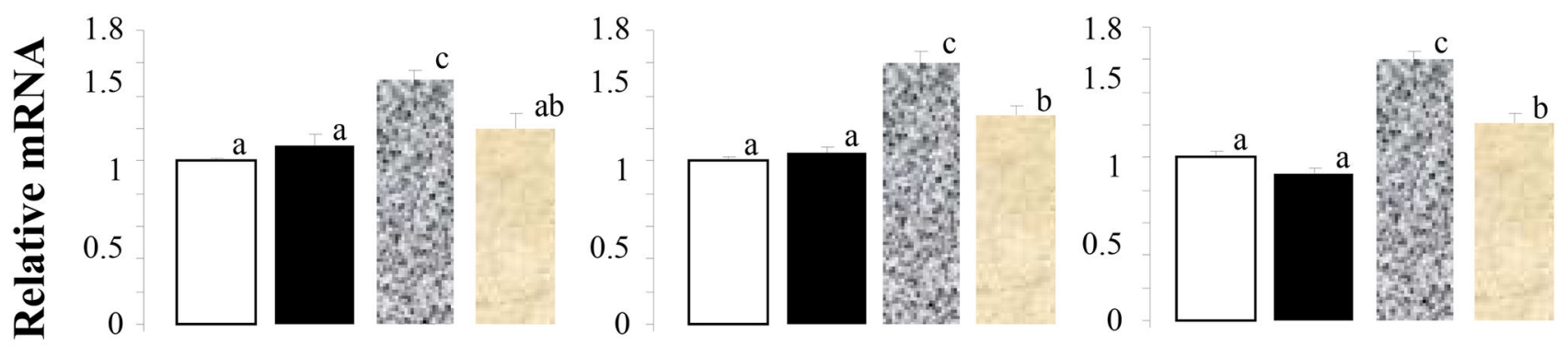

Figure 4. High Fat/High Fructose diet increases Pten, Tau and App in hippocampus and cortex. Open bar, control diet; solid bar, control diet plus cinnamon, mottled gray bar, HF/HFr diet; gray bar, HF/HFr diet plus cinnamon. Values are mean \pm SE for 8 to 10 rats. Different letters denote significant differences among groups, $p<0.05$.

doi: 10.1371/journal.pone.0083243.g004

supplementation reverses some, but not all, the deleterious effects of the HF/HFr diet in liver and muscle [21]. In muscle, there were no significant effects of $\mathrm{CN}$ on Insr, Irs1 and Irs2 in animals consuming the control diet whereas all three were reduced in the animals consuming the HF/HFr diet. Negative effects of the HF/HFr diet were prevented in the animals consuming the HF/HFr diet plus $\mathrm{CN}$. Contrary to the effects observed for muscle, in the hippocampus and cortex, consumption of the HF/HFr diet led to increases in Ir, Irs1 and Irs2 that were not prevented by the consumption of $\mathrm{CN}$ (Figure 2). This apparent anomaly is consistent with the study demonstrating that IRS 2 is a negative regulator of memory function and restricts dendritic spine generation [61]. Deletion of Irs2 reduces amyloid deposition and rescues behavioral deficits in APP transgenic mice [62] and increases in Irs2 in this study are consistent with negative effects on learning and memory. Although in a nonsignificative manner, cinnamon blunted the HF/HFr diet effects on anxiety in EPM.

Cinnamon also prevented the decreases in Glut1 in animals consuming the HF/HFr diet plus CN. Similar effects were observed for Glut3, also named the "brain glucose transporter" because it is expressed at high levels in nerves and neural tissue [63]. Cinnamon increased the expression of Gys1 not only in the control animals but also reversed the decreases in
Gys1 expression in the cortex in the animals consuming the $\mathrm{HF} / \mathrm{HFr}$ diet. This suggests that cinnamon may have corrected some metabolic effects of insulin resistance.

In addition, $\mathrm{CN}$ alleviated the negative effects of the HF/HFr diet on Alzheimer-related variables in the brain that we analyzed. Recent studies showed that $\mathrm{CN}$ alleviates factors associated with Alzheimer's disease and memory loss by blocking and reversing TAU formation and blocking the effects of amyloid precursor protein [28]. An aqueous extract of Ceylon cinnamon (C. zeylanicum) was shown to inhibit hallmark signs of $A D$ including TAU aggregation and the formation of TAU filaments [16]. TAU filaments removed from the brain of a person who died with $A D$ were also disassociated by a $C N$ extract. A type A-linked procyanidin trimer purified from the aqueous extract was shown to contain a significant portion of the inhibitory activity. This type A trimer has subsequently been purified and identified as cinnamtannin B-1, MW 864 (Richard Anderson, unpublished results). However, there are other active components in cinnamon and Lu et al. [64] demonstrated that both type A- and B-type proanthocyanidins may improve insulin sensitivity. Cinnamon proanthocyanidins were also shown to be the major anti-diabetic components of a cinnamon water extract in the prevention of the misfolding of 
human islet amyloid polypeptide, a proposed causative factor for type 2 diabetes [60].

A limitation of this study is that additional measurements involving protein levels and protein modification levels were not measured. This study was designed to demonstrate that changes in insulin sensitivity due to diet and cinnamon are associated with changes in behavior and changes in the brain related to insulin sensitivity. This objective was accomplished, however, future studies should include protein related changes.

\section{Conclusion}

In summary, this study demonstrated that short-term changes in diet led to not only changes in insulin sensitivity and behavior but also early changes in mRNA coding for proteins related to memory including glycogen synthase kinase $3 \beta$, glycogen synthase, PTEN, TAU, and APP that could be prevented or alleviated due to the intake of $\mathrm{CN}$. The $\mathrm{CN}$ fed rats were more active in a $Y$ maze test than rats fed the control and $\mathrm{HF} / \mathrm{HFr}$ diets. The HF/HFr diet fed rats showed greater anxiety in an elevated plus maze test that was lessened by feeding $\mathrm{CN}$. In conclusion, the negative effects of a HF/HFr diet on brain insulin signaling and behavior were alleviated by $\mathrm{CN}$ suggesting neuroprotective effects of $\mathrm{CN}$ associated with whole body improved insulin sensitivity and related changes in the

\section{References}

1. Grundy SM (2008) Metabolic syndrome pandemic. Arterioscler Thromb Vasc Biol 28: 629-636. doi:10.1161/ATVBAHA.107.151092. PubMed: 18174459.

2. Convit A (2005) Links between cognitive impairment in insulin resistance: an explanatory model. Neurobiol Aging 26 Suppl 1: 31-35. doi:10.1016/j.neurobiolaging.2005.09.018. PubMed: 16246463.

3. Talbot K, Wang HY, Kazi H, Han LY, Bakshi KP et al. (2012) Demonstrated brain insulin resistance in Alzheimer's disease patients is associated with IGF-1 resistance, IRS-1 dysregulation, and cognitive decline. J Clin Invest 122: 1316-1338. doi:10.1172/JCI59903. PubMed: 22476197.

4. Craft S, Asthana S, Cook DG, Baker LD, Cherrier M et al. (2003) Insulin dose-response effects on memory and plasma amyloid precursor protein in Alzheimer's disease: interactions with apolipoprotein E genotype. Psychoneuroendocrinology 28: 809-822. doi:10.1016/S0306-4530(02)00087-2. PubMed: 12812866.

5. Gupta A, Bisht B, Dey CS (2011) Peripheral insulin-sensitizer drug metformin ameliorates neuronal insulin resistance and Alzheimer's-like changes. Neuropharmacology 60: 910-920. doi:10.1016/j.neuropharm. 2011.01.033. PubMed: 21277873.

6. Rivera EJ, Goldin A, Fulmer N, Tavares R, Wands JR, de la Monte SM (2005) Insulin and insulin-like growth factor expression and function deteriorate with progression of Alzheimer's disease: link to brain reductions in acetylcholine. J Alzheimers Dis 8: 247-268. PubMed: 16340083.

7. de la Monte SM, Wands JR (2005) Review of insulin and insulin-like growth factor expression, signaling, and malfunction in the central nervous system: relevance to Alzheimer's disease. J Alzheimers Dis 7: 45-61. PubMed: 15750214.

8. Lester-Coll N, Rivera EJ, Soscia SJ, Doiron K, Wands JR, de la Monte SM (2006) Intracerebral streptozotocin model of type 3 diabetes: relevance to sporadic. Journal of Alzheimer'S Disease - J Alzheimers Dis 9: 13-33.

9. de la Monte SM, Wands JR (2008) Alzheimer's disease is type 3 diabetes-evidence reviewed. J Diabetes Sci Technol 2: 1101-1113. PubMed: 19885299.

10. Stranahan AM, Norman ED, Lee K, Cutler RG, Telljohann RS et al. (2008) Diet-induced insulin resistance impairs hippocampal synaptic plasticity and cognition in middle-aged rats. Hippocampus 18: 1085-1088. doi:10.1002/hipo.20470. PubMed: 18651634 brain. The consumption of foods or diets that lead to decreased insulin sensitivity may lead not only to changes in insulin related variables but also possible early changes in behavior that can be prevented or alleviated by $\mathrm{CN}$. Additional studies are needed to further characterize the proteins and metabolites associated with these changes.

\section{Acknowledgements}

We are indebted to Renaud Maury and Nadine Fidier who participated in the conditioning of the animals.

Disclaimer: Mention of trade names or commercial products in this publication is solely for the purpose of providing specific information and does not imply recommendation or endorsement by the U.S. Department of Agriculture.

The USDA is an equal opportunity provider and employer.

\section{Author Contributions}

Conceived and designed the experiments: RAA BQ FC AMR. Performed the experiments: BQ FC LP. Analyzed the data: RAA BQ FC LP AMR. Contributed reagents/materials/analysis tools: RAA BQ FC AMR. Wrote the manuscript: RAA BQ FC AMR.

11. Khan A, Safdar M, Khan Ali, Khattak KN, Anderson RA (2003) Cinnamon improves glucose and lipids of people with type 2 diabetes. Diabetes Care 26: 3215-3218. doi:10.2337/diacare.26.12.3215. PubMed: 14633804.

12. Jarvill-Taylor KJ, Anderson RA, Graves DJ (2001) A hydroxychalcone derived from cinnamon functions as a mimetic for insulin in 3T3-L1 adipocytes. J Am Coll Nutr 20: 327-336. doi: 10.1080/07315724.2001.10719053. PubMed: 11506060.

13. Wang JG, Anderson RA, Graham GM III, Chu MC, Sauer MV et al. (2007) The effect of cinnamon extract on insulin resistance parameters in polycystic ovary syndrome: a pilot study. Fertil Steril 88: 240-243. doi:10.1016/j.fertnstert.2006.11.082. PubMed: 17296187.

14. Cao H, Polansky MM, Anderson RA (2007) Cinnamon extract and polyphenols affect the expression of tristetraprolin, insulin receptor, and glucose transporter 4 in mouse 3T3-L1 adipocytes. Arch Biochem Biophys 459: 214-222. doi:10.1016/j.abb.2006.12.034. PubMed: 17316549.

15. Ziegenfuss TN, Hofheins JE, Mendel RW, Landis J, Anderson RA (2006) Effects of a water-soluble cinnamon extract on body composition and features of the metabolic syndrome in pre-diabetic men and women. J Int Soc Sports Nutr 3:45-53

16. Peterson DW, George RC, Scaramozzino F, Lapointe NE, Anderson RA et al. (2009) Cinnamon Extract Inhibits Tau Aggregation Associated with Alzheimer's Disease. In Vitro - J Alzheimers Dis 17: 585-587.

17. Lu J, Zhang K, Nam S, Anderson RA, Jove R, Wen W (2010) Novel angiogenesis inhibitory activity in cinnamon extract blocks VEGFR2 kinase and downstream signaling. Carcinogenesis 31: 481-488. PubMed: 19969552

18. Qin B, Polansky MM, Anderson RA (2010) Cinnamon extract regulates plasma levels of adipose-derived factors and expression of multiple genes related to carbohydrate metabolism and lipogenesis in adipose tissue of fructose-fed rats. Horm Metab Res 42: 187-193. doi:10.1055/ s-0029-1242746. PubMed: 19937569.

19. Qin B, Panickar KS, Anderson RA (2010) Cinnamon: potential role in the prevention of insulin resistance, metabolic syndrome, and type 2 diabetes. J Diabetes Sci Technol 4: 685-693. PubMed: 20513336.

20. Couturier K, Batandier C, Awada M, Hininger-Favier I, Canini F, Anderson RA et al. (2010) Cinnamon improves insulin sensitivity and alters the body composition in an animal model of the metabolic syndrome. Arch Biochem Biophys 501: 158-161. doi:10.1016/j.abb. 2010.05.032. PubMed: 20515642 
21. Couturier K, Qin B, Batandier C, Awada M, Hininger-Favier I, Canini F et al. (2011) Cinnamon increases liver glycogen in an animal model of insulin resistance. Metabolism 60: 1590-1597. doi:10.1016/j.metabol. 2011.03.016. PubMed: 21550075.

22. Anderson RA, Broadhurst CL, Polansky MM, Schmidt WF, Khan A et al. (2004) Isolation and characterization of polyphenol type-A polymers from cinnamon with insulin-like biological activity. J Agric Food Chem 52: 65-70. doi:10.1021/jf034916b. PubMed: 14709014

23. Killday KB, Davey MH, Glinski JA, Duan P, Veluri R, Proni G et al. (2011) Bioactive A-type proanthocyanidins from Cinnamomum cassia. $J$ Nat Prod 74: 1833-1841. doi:10.1021/np1007944. PubMed: 21875098.

24. Cao H, Kelly MA, Kari F, Dawson HD, Urban JF Jr. et al. (2007) Green tea increases anti-inflammatory tristetraprolin and decreases proinflammatory tumor necrosis factor mRNA levels in rats. J Inflamm (Lond) 4: 1. doi:10.1186/1476-9255-4-1. PubMed: 17207279.

25. Cao H, Graves DJ, Anderson RA (2010) Cinnamon extract regulates glucose transporter and insulin-signaling gene expression in mouse adipocytes. Phytomedicine 17: 1027-1032. doi:10.1016/j.phymed. 2010.03.023. PubMed: 20554184.

26. Preuss HG, Echard B, Polansky MM, Anderson R (2006) Whole cinnamon and aqueous extracts ameliorate sucrose-induced blood pressure elevations in spontaneously hypertensive rats. J Am Coll Nutr 25: 144-150. doi:10.1080/07315724.2006.10719525. PubMed: 16582031.

27. Dellu F, Fauchey V, Le MM, Simon H (1997) Extension of a new twotrial memory task in the rat: influence of environmental context on recognition processes. Neurobiol Learn Mem 67: 112-120. doi:10.1006/ nlme.1997.3746. PubMed: 9075239.

28. Frydman-Marom A, Levin A, Farfara D, Benromano T, Scherzer-Attali $\mathrm{R}$ et al. (2011) Orally administrated cinnamon extract reduces betaamyloid oligomerization and corrects cognitive impairment in Alzheimer's disease animal models. PLOS ONE 6: e16564. doi: 10.1371/journal.pone.0016564. PubMed: 21305046.

29. Ryu BR, Ko HW, Jou I, Noh JS, Gwag BJ (1999) Phosphatidylinositol 3-kinase-mediated regulation of neuronal apoptosis and necrosis by insulin and IGF-I. J Neurobiol 39: 536-546. doi:10.1002/ (SICI)1097-4695(19990615)39:4. PubMed: 10380075

30. Woods SC, Seeley RJ, Baskin DG, Schwartz MW (2003) Insulin and the blood-brain barrier. Curr Pharm Des 9: 795-800. doi: 10.2174/1381612033455323. PubMed: 12678878.

31. Schiöth HB, Craft S, Brooks SJ, Frey WH, Benedict C (2012) Brain insulin signaling and Alzheimer's disease: current evidence and future directions. Mol Neurobiol 46: 4-10. doi:10.1007/s12035-011-8229-6. PubMed: 22205300.

32. Kim B, Feldman EL (2012) Insulin resistance in the nervous system Trends Endocrinol Metab 23: 133-141. doi:10.1016/j.tem.2011.12.004. PubMed: 22245457

33. Benedict C, Brooks SJ, Kullberg J, Burgos J, Kempton MJ et al. (2012) Impaired insulin sensitivity as indexed by the HOMA score is associated with deficits in verbal fluency and temporal lobe gray matter volume in the elderly. Diabetes Care 35: 488-494. doi:10.2337/ dc11-2075. PubMed: 22301128

34. Parra MA, Abrahams S, Fabi K, Logie R, Luzzi S, Della SS (2009) Short-term memory binding deficits in Alzheimer's disease. Brain 132: 1057-1066. PubMed: 19293236

35. Kosari S, Badoer E, Nguyen JC, Killcross AS, Jenkins TA (2012) Effect of western and high fat diets on memory and cholinergic measures in the rat. Behav Brain Res 235: 98-103. doi:10.1016/j.bbr.2012.07.017. PubMed: 22820146

36. Bruehl H, Sweat V, Hassenstab J, Polyakov V, Convit A (2010) Cognitive impairment in nondiabetic middle-aged and older adults is associated with insulin resistance. J Clin Exp Neuropsychol 32: 487-493. doi:10.1080/13803390903224928. PubMed: 20524222.

37. Crawford $P$ (2009) Effectiveness of cinnamon for lowering hemoglobin A1C in patients with type 2 diabetes: a randomized, controlled trial. J Am Board Fam Med 22: 507-512. doi:10.3122/jabfm.2009.05.080093. PubMed: 19734396.

38. Akilen R, Tsiami A, Devendra D, Robinson N (2010) Glycated haemoglobin and blood pressure-lowering effect of cinnamon in multiethnic Type 2 diabetic patients in the UK: a randomized, placebocontrolled, double-blind clinical trial. Diabet Med 27: 1159-1167. doi: 10.1111/j.1464-5491.2010.03079.x. PubMed: 20854384.

39. Lu T, Sheng H, Wu J, Cheng Y, Zhu J, Chen Y (2012) Cinnamon extract improves fasting blood glucose and glycosylated hemoglobin level in Chinese patients with type 2 diabetes. Nutr Res 32: 408-412. doi:10.1016/j.nutres.2012.05.003. PubMed: 22749176.

40. Soulis G, Papalexi E, Kittas C, Kitraki E (2007) Early impact of a fatenriched diet on behavioral responses of male and female rats. Behav
Neurosci 121: 483-490. doi:10.1037/0735-7044.121.3.483. PubMed: 17592939.

41. Prasad A, Prasad C (1996) Short-term consumption of a diet rich in fat decreases anxiety response in adult male rats. Physiol Behav 60: 1039-1042. doi:10.1016/S0031-9384(96)00135-7. PubMed: 8873290.

42. White CL, Pistell PJ, Purpera MN, Gupta S, Fernandez-Kim SO et al. (2009) Effects of high fat diet on Morris maze performance, oxidative stress, and inflammation in rats: contributions of maternal diet. Neurobiol Dis 35: 3-13. doi:10.1016/j.nbd.2009.04.002. PubMed: 19374947

43. Stranahan AM, Norman ED, Lee K, Cutler RG, Telljohann RS et al. (2008) Diet-induced insulin resistance impairs hippocampal synaptic plasticity and cognition in middle-aged rats. Hippocampus 18: 1085-1088. doi:10.1002/hipo.20470. PubMed: 18651634

44. Cruz AP, Frei F, Graeff FG (1994) Ethopharmacological analysis of rat behavior on the elevated plus-maze. Pharmacol Biochem Behav 49: 171-176. doi:10.1016/0091-3057(94)90472-3. PubMed: 7816869.

45. Souza CG, Moreira JD, Siqueira IR, Pereira AG, Rieger DK et al. (2007) Highly palatable diet consumption increases protein oxidation in rat frontal cortex and anxiety-like behavior. Life Sci 81: 198-203. doi: 10.1016/j.Ifs.2007.05.001. PubMed: 17574275.

46. Legendre A, Harris RB (2006) Exaggerated response to mild stress in rats fed high-fat diet. Am J Physiol Regul Integr Comp Physiol 291: R1288-R1294. doi:10.1152/ajpregu.00234.2006. PubMed: 16793938.

47. Buwalda B, Blom WA, Koolhaas JM, van DG (2001) Behavioral and physiological responses to stress are affected by high-fat feeding in male rats. Physiol Behav 73: 371-377. doi:10.1016/ S0031-9384(01)00493-0. PubMed: 11438364.

48. Park CR (2001) Cognitive effects of insulin in the central nervous system. Neurosci Biobehav Rev 25: 311-323. doi:10.1016/ S0149-7634(01)00016-1. PubMed: 11445137.

49. Frisardi V, Solfrizzi V, Capurso C, Imbimbo BP, Vendemiale G et al. (2010) Is insulin resistant brain state a central feature of the metaboliccognitive syndrome? J Alzheimers Dis 21: 57-63. PubMed: 20421697.

50. Reger MA, Watson GS, Green PS, Baker LD, Cholerton B et al. (2008) Intranasal insulin administration dose-dependently modulates verbal memory and plasma amyloid-beta in memory-impaired older adults. J Alzheimers Dis 13: 323-331. PubMed: 18430999.

51. Park CR, Seeley RJ, Craft S, Woods SC (2000) Intracerebroventricular insulin enhances memory in a passive-avoidance task. Physiol Behav 68: 509-514. doi:10.1016/S0031-9384(99)00220-6. PubMed: 10713291.

52. Cruz NF, Dienel GA (2002) High glycogen levels in brains of rats with minimal environmental stimuli: implications for metabolic contributions of working astrocytes. J Cereb Blood Flow Metab 22: 1476-1489. PubMed: 12468892

53. Gibbs ME, Hutchinson DS (2012) Rapid turnover of glycogen in memory formation. Neurochem Res 37: 2456-2463. doi:10.1007/ s11064-012-0805-2. PubMed: 22664636.

54. Brown AM, Ransom BR (2007) Astrocyte glycogen and brain energy metabolism. Glia 55: 1263-1271. doi:10.1002/glia.20557. PubMed: 17659525

55. Gonzales MM, Tarumi T, Miles SC, Tanaka H, Shah F, Haley AP (2010) Insulin sensitivity as a mediator of the relationship between BMI and working memory-related brain activation. Obesity (Silver Spring) 18: 2131-2137. doi:10.1038/oby.2010.183. PubMed: 20814415.

56. Qutub AA, Hunt CA (2005) Glucose transport to the brain: a systems model. Brain Res Brain. Res Rev 49: 595-617. doi:10.1016/ j.brainresrev.2005.03.002.

57. Roberson ED, Scearce-Levie K, Palop JJ, Yan F, Cheng IH et al. (2007) Reducing endogenous tau ameliorates amyloid beta-induced deficits in an Alzheimer's disease mouse model. Science 316: 750-754. doi:10.1126/science.1141736. PubMed: 17478722.

58. Takashima A (2012) GSK-3beta and memory formation. Front - Journal of Mol Neuroscience 5: 47. PubMed: 22536172.

59. Holmes C, Boche D, Wilkinson D, Yadegarfar G, Hopkins $V$ et al. (2008) Long-term effects of Abeta42 immunisation in Alzheimer's disease: follow-up of a randomised, placebo-controlled phase I trial. Lancet 372: 216-223. doi:10.1016/S0140-6736(08)61075-2. PubMed: 18640458

60. Jiao L, Zhang X, Huang L, Gong H, Cheng B et al. (2013) Proanthocyanidins are the major anti-diabetic components of cinnamon water extract. Food Chem Toxicol 56: 398-405. doi:10.1016/j.fct. 2013.02.049. PubMed: 23499750

61. Irvine EE, Drinkwater L, Radwanska K, Al-Qassab H, Smith MA et al. (2011) Insulin receptor substrate 2 is a negative regulator of memory formation. Learn Mem 18: 375-383. doi:10.1101//m.2111311. PubMed: 21597043. 
62. Killick R, Scales G, Leroy K, Causevic M, Hooper C et al. (2009) Deletion of Irs2 reduces amyloid deposition and rescues behavioural deficits in APP transgenic mice. Biochem Biophys Res Commun 386: 257-262. doi:10.1016/j.bbrc.2009.06.032. PubMed: 19523444.

63. Stuart CA, Ross IR, Howell ME, McCurry MP, Wood TG et al. (2011) Brain glucose transporter (Glut3) haploinsufficiency does not impair mouse brain glucose uptake. Brain Res 1384: 15-22. doi:10.1016/ j.brainres.2011.02.014. PubMed: 21316350.

64. Lu Z, Jia Q, Wang R, Wu X, Wu Y et al. (2011) Hypoglycemic activities of $\mathrm{A}$ - and B-type procyanidin oligomer-rich extracts from different Cinnamon barks. Phytomedicine 18: 298-302. doi:10.1016/j.phymed. 2010.08.008. PubMed: 20851586. 